Ann. Biol. anim. Bioch. Biophys., 1979, 19 (4 B), 1197-1209.

\title{
Differentiation of the fetal gonad of Macaca fascicularis with special reference to the testis
}

\author{
par D. C. DANG, J. P. FOUQUET * \\ Laboratoire d'Anatomie, UER Biomédicale, \\ 45 rue des Saints-Pères, 75270 Paris Cedex \\ * Laboratoire de Physiologie de la Reproduction Université Paris VI, \\ 4 place Jussieu, 75230 Paris, France.
}

Summary. The histogenesis of the fetal gonad of Macaca fascicularis was studied from the genital ridge stage in 24 fetuses (16 males and 8 females) aged 36 to 55 days. Observations were carried out using light and electron microscopy on serial sections of the specimens embedded in epon. The genital ridge was formed of a mesenchymal blastema covered by a peripheral epithelium. The first stages of differentiation ( 37 to 39 days) were the same in the testis and the ovary. We observed an antero posterior and centrifugal differentiation of the sex cords in the blastema from the peripheral mesenchyma of the mesonephric ducts at the anterior pole of the gonad. The mesonephric ducts and the peripheral epithelium contributed very little directly to sex cord formation (PI. I). The separation of the newly formed cords was accelerated by vascular invasion from the mesonephros. Definitive testicular structure was acquired between 40 and 43 days. The presence of the peripheral testicular artery was a deferminant of the growth of the tunica albuginea (PI. III). No large changes were observed in the ovary between 40 and 55 days (PI. IV).

\section{Introduction.}

The gonads of the mammalian fetus develop from two gonadal primordia forming the genital ridges on the ventral side of the mesonephros. At the very beginning of their development, the germ and somatic cells in the future testis and ovary lack topographical organization. This has been called «the indifferent stage " of the fetal gonad (Raynaud, 1969). From this stage on, the gonads differentiate earlier in males than in females (Jost, 1971 ; Peters, 1976). The histogenesis of the seminiferous cords of the testis was described in several species of mammals more than a hundred years ago, and more recently by Merchant (1975), Pelliniemi (1975) and Wartenberg (1978) using electron microscopy.

Little work has been done on this subject in non-human primates. The structure of the fetal testis of the rhesus macaque, Macaca mulatfa, has been described shortly after differentiation using light microscopy (Van Wagenen and Simpson, 1965). However, owing to the fact that it is difficult to adequately fix fetal gonads for conventional histology, no definite pattern of development has been defined for germ and 
somatic cell development (Jost, 1972). We therefore decided to study the festicular development of the crab-eating macaque, Macaca fascicularis, using semithin sections under light microscopy and ultrathin sections under electron microscopy. A comparison with some ovaries permitted us to determine the originality of testicular development.

\section{Material and methods.}

We obtained 16 male and 8 female fetuses 36 to 55 days old by cesarian (Dang, $1977 b$ ). Fetal age was determined by assuming that fertilization occurred on day 13 of the menstrual cycle since the females had access to the males for only 24 or $48 \mathrm{hrs}$ on days 12 and 13 of the cycle (Dang, 1977a). The sex of the fetus was ascertained by the amount of « sexual chromatin » or «Barr bodies » on the cells of the amniotic sac.

After dissection, the whole mesonephros-gonad complex was immediately taken and fixed according to the technique of Fouquet ef al. (1978). The serial semithin sections were stained with toluidine blue then observed with a light microscope. The thin sections were contrasted with uranyl acetate-lead citrate and examined under an electron microscope (Jem 100 B or Phillips 201 C).

\section{Results.}

The examination of both types of sections furnished complementary data which are presented simultaneously for each age period.

\section{1) 36 to 37-day gonad.}

The transition, at this age, from the genital ridge to the young indifferent gonad is shown in figures 1 and 2 . The genital ridge was a simple longitudinal protuberance on the ventral side of the mesonephros. It was composed of a mesenchymal non-vas-

\section{PLATE 1}

36 to 39-day gonad.

Semithin tissue sections stained with toluidine blue. $\Varangle$ 250. $\mathrm{e}=$ peripheral epithelium, g.b. $=$ gonadal blastema, $\mathrm{G}=$ gonocyte, $\mathrm{m} . \mathrm{t} .=$ mesonephric tubes.

FIG. 1. - A 36-day male genifal ridge.

FIG. 2. - A 37-day indifferent gonad (ovary) showing slight enlargement of the dark gonadal blastema surrounded by the clear peripheral epithelium.

FIGS 3, 4, 5. - Samples of serial cross-sections through the same 38-day testis. Fig. 3 : Sex cords begin to emerge in the gonadal blastema closely applied against the mesonephric tubes of the gonadal anterior pole. Fig. 4 : Patent sex cords in the neighboring anterior region of the gonad. Arrow indicates future testicular artery. Fig. 5 : Sex cords are less evident in the posterior of the gonad.

FIGS 6, 7. - Cross-sections of the anterior of a 39-day testis. The dark perimesonephric mesenchymal cells seem to invade and enlarge the gonadal blastema. Arrows indicate evident centrifugal sex cord differentiation (fig. 7). 
cularized mass, the central blastema, containing most of the gonocytes and covered by a peripheral epithelium. This gonadal anlage showed the same organization throughout. It was separated from the mesonephric ducts by a loose, vascularized mesenchymal region containing some late or stray gonocytes.

The mesenchymal cells of the blastema were beginning to consolidate but did not yet form the sexual cords. Some of these cells were lying against the approximately spherical gonocytes, which were about twice as big as they were.

The architecture of the gonadal peripheral epithelium was different from that of the mesothelium to which it was attached. The mesothelium was a simple, flat epithelium, lying on a basal lamina which covered the mesonephros. The peripheral epithelium contained more mitosis, was irregularly stratified and has no basal lamina. Its cells were higher, their major axis being oriented towards the depth of the genital ridge. Some rare gonocytes were seen among these cells which, however, formed no cord anlages and were lying directly against the mesenchymal cells of the blastema. The distinction between these two regions of the young gonad was entirely based on differences in affinity for toluidine blue, i.e. the peripheral epithelium stained weakly, while the blastema stained deeply (fig. 2). Thus, in spite of the absence of specific ultrastructural characteristics, the fate of gonad somatic cells could be determined. On the other hand, the gonocytes were easily recognizable by their large size, weak staining, paucity of cytoplasmic organelles, mitochondria with tubular cristae and a large nucleus with a large aveolar nucleolus.

\section{2) 38 to 39-day gonad.}

Within 2 days, the genital ridge became an indifferent gonad which had practically doubled in volume and freed itself from the mesonephros (figs $2,3,4,5$ ). The structure of male or female gonads at this indifferent stage was basically the same as earlier. The peripheral epithelium was only slightly more developed and did not form sex cords. On the other hand, the mesenchymal blastema was both denser and more irregularly split (fig. 4). Some sex cords were seen to be forming within the blastema. They contained most of the gonocytes; however, some gonocytes persisted in the peripheral epithelium.

Serial sections showed that cord formation began in the anterior region of the gonad. At this anterior pole, the 4 to 6 better developed mesonephric ducts formed a proximal loop which entered into contact with the blastema and invaginated it more or less deeply (figs $3,6,7$ ). The sex cords began to form at the contact of these mesone-

\section{PLATE ॥}

Electron micrograph of the anterior region of a 38-day testis.

FIG. 8. - The peripheral stratified epithelium (above) and the gonadal blastema (below) are only separated by large irregular spaces (dotted line) occupied by collagenous fibers. No ultrastructural differences or basement laminae are visible. $\times 3330$.

FIG. 9. - Depth of gonadal blastema. The newly formed sex cords are underlined by traces of basement laminae (arrows) and contain the future Sertoli cells (S) encircling gonocytes (G). $\times 9000$ 
(x)

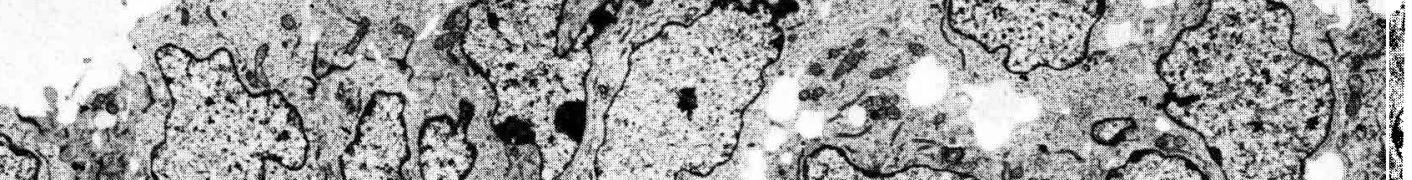

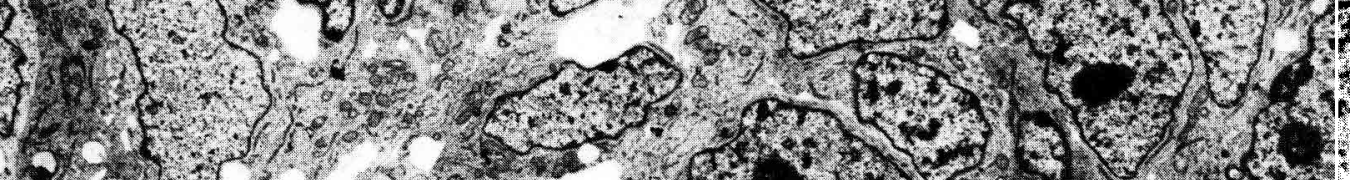

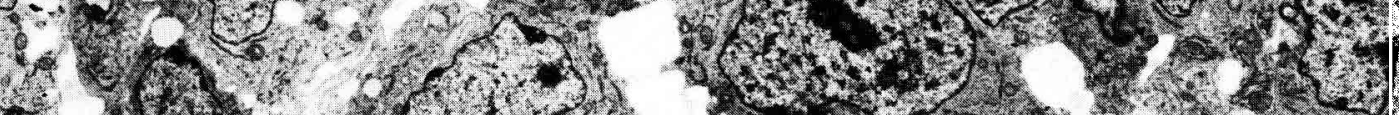

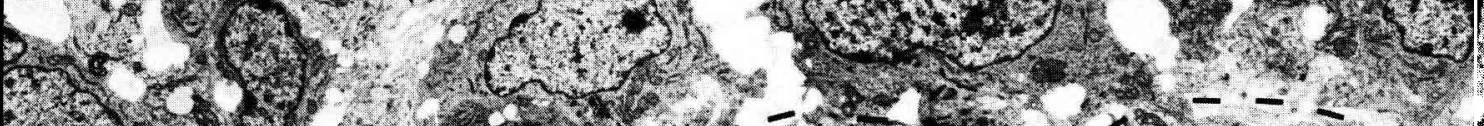

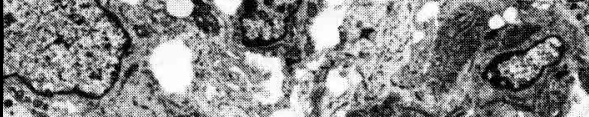

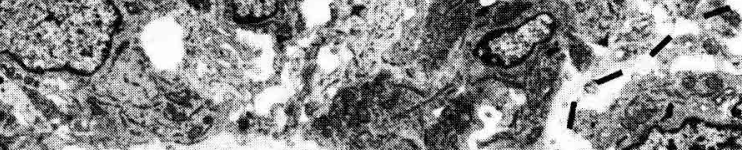

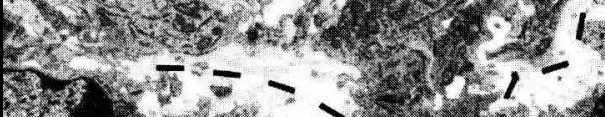

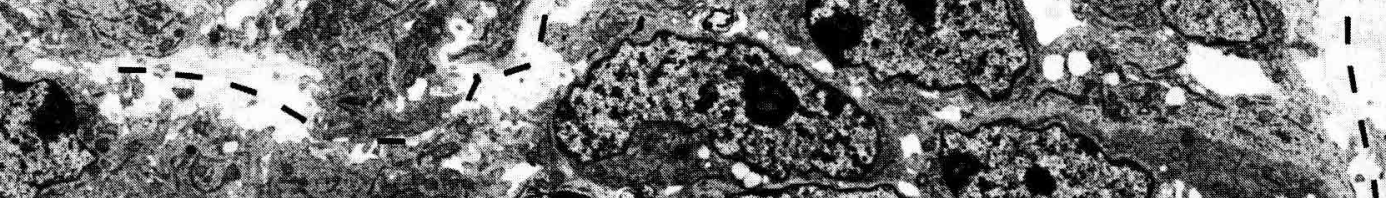

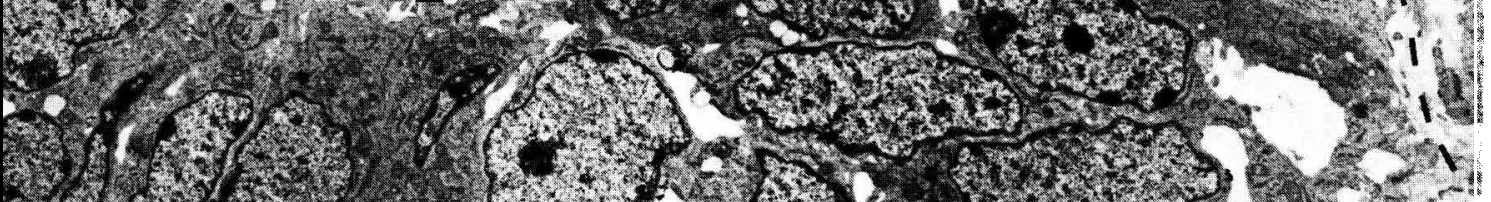

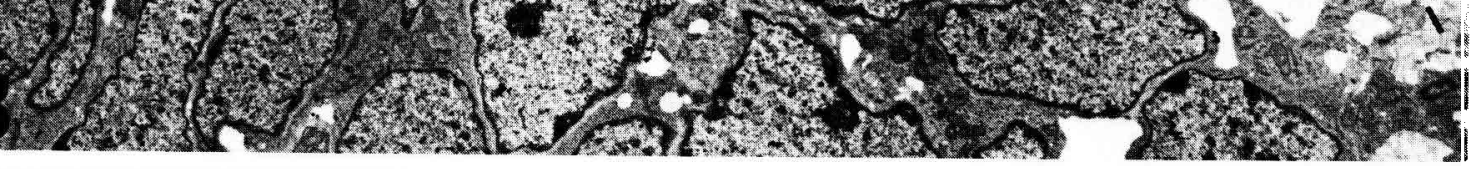
(6)

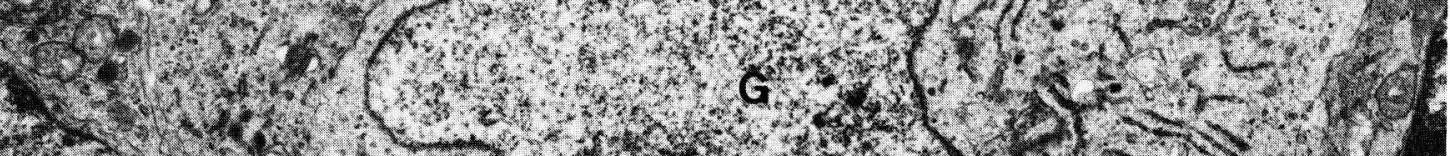
$x^{2}=x^{4}+2$

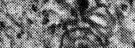
.

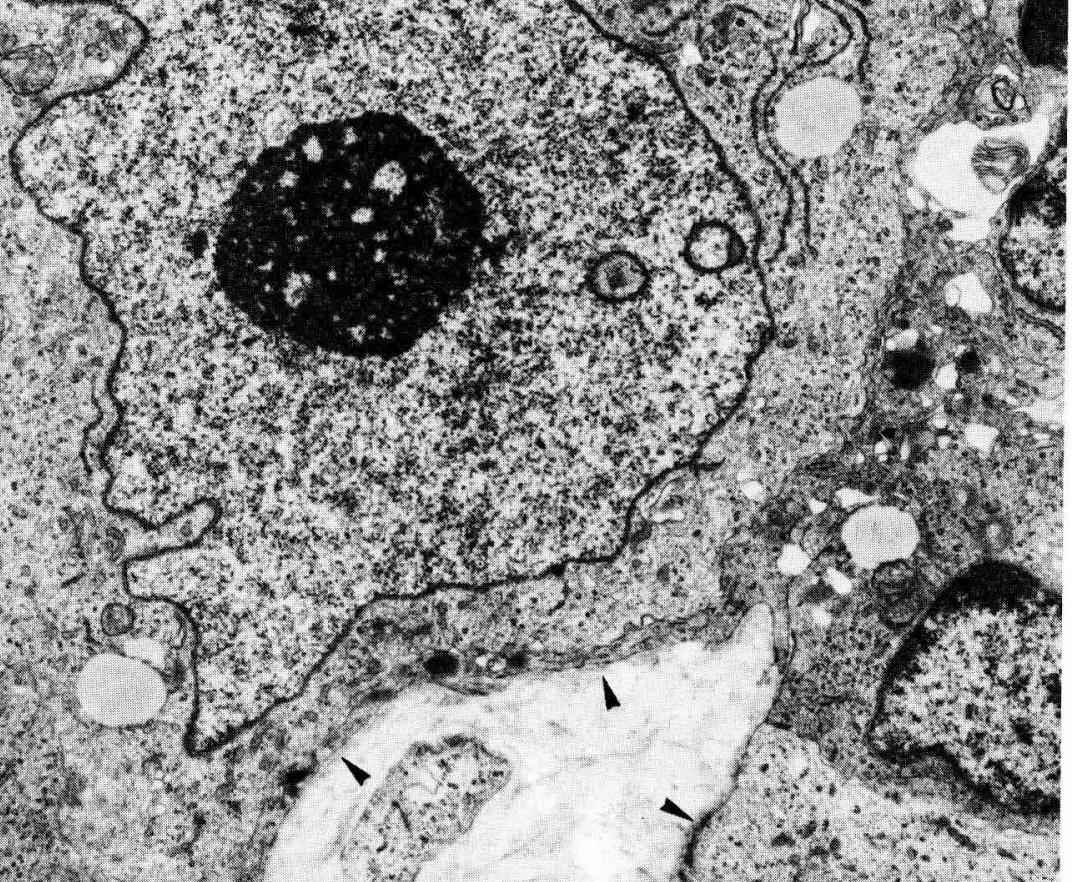


phric ducts and in their immediate vicinity. The organization of the cords of the blastema was then gradually extended closer to the posterior pole of the gonad (figs $3,4,5$ ). Cord formation also progressed from the depth of the blastema towards the periphery of the gonad (fig. 7).

Thus, during differentiation of male or female gonads, the sex cords, constituted by the consolidation of 2 to 5 layers of mesenchymal cells, were first individualized in depth in the anterior region. Their limits were clear and already outlined by a discontinuous basal lamina (fig. 9). These limits were less evident towards the gonadal periphery, owing to the absence of the basal lamina. They disappeared at the peripheral epithelium (fig. 8). Finally, the spaces separating the forming cords were successively occupied by rare mesenchymal cells and collagen fibers (fig. 9), then by mesonephric capillaries (fig. 4). These capillaries, which developed from the interior to the periphery of the gonad, thus contributed secondarily to the separation of the cords by a vascularized interstitium.

These observations clearly showed that differentiation of the gonadal sex cords of the macaque testis or ovary was antero-posterior and centrifugal. This process was only visible during 2 or 3 days (days 37 to 40 ); it originated at the contact of the mesonephric ducts at the anterior pole of the gonad and apparently involved a perimesonephric mesenchymal differentiation excluding direct participation of the mesonephric duct cells. The ultrastructure of the walls of these ducts remained intact and was always outlined by a continuous basal lamina. No leakage of tubule or glomerulate cells was observed.

The relationship of the peripheral epithelium and the gonadal blastema was difficult to evaluate. The only difference between the two regions was their affinity for toluidine blue. However, in the gonadal peripheral region, the epithelium and mesenchymal cells retained a similar ultrastructure. They tended to be tangentially arranged and were often in mutual contact. The only reference point indicating their approximate limit was their local separation by large spaces rich in collagenous fibers (fig. 8) ; this limit corresponded grossly to the future tunica albuginea. Such an indefinite boundary would not exclude peripheral epithelium participation in the formation of the sex cords, although the centrifugal differentiation observed would not suggest it.

PLATE III

The end of testicular differentiation.

FIG. 10. - A 40-day testis showing centrifugal arrangement of the sex cords and of the vascularized interstitium. Arrow indicates the future testicular artery. A thin tunica albuginea $(a)$ is emerging between the sex cords and the outermost layer of the peripheral epithelium. $\times 250$.

FIG. 11. - Typical organization of a 43-day testis showing the simple flat peripheral epithelium (e), the large tunica albuginea (a) including the testicular artery (arrow), and the anastomosed sex cords separated by a large interstitium. $\times 250$.

FIG. 12. - At 43 days, the sex cords are completely surrounded by a continuous basement lamina (arrow). Most gonocytes (G) are almost entirely encircled by future Sertoli cells (S). $\times 10000$. 

3) 40 to 43-day gonad.

Fetal sex differentiation appeared at 40 days.

a) Testis. The male gonad was definitively organized within several days (fig. 10 , 11). Centrifugal differentiation of the sex cords was triggered within the blastema and the cords separated from the peripheral epithelium. This separation was due to the gradual extension of the basal laminae around the sex cords up to their periphery. Moreover, a basal lamina appeared under the topmost layer of the peripheral epithelium. The deep layers of this epithelium contributed to the formation of the tunica albuginea, which first appeared to be constituted of 2 to 3 layers of flat cells inserted between the surface epithelium and the sex cords (fig. 10). However, it was difficult to observe the organization in this transitional region, and certain mesenchymal cells of the blastema periphery might not have been incorporated into the cords and contributed to the anlage of the tunica albuginea.

At 43 days (fig. 11), the male sex cords presented a characteristic organization. They were enveloped by a continuous basal lamina (fig. 12), appeared thinner and more regular, and were reduced to a 2 to 3 -layer thickness of somatic cells. Gonocyte encirclement by future Sertoli cells was in an advanced stage (fig. 12). Almost onehalf of the gonocytes were not found lying on the basal lamina of the cords ; they were all separated from it at 50 to 55 days.

Finally, the mesonephric vessels, accompanied by a procession of mesenchymal cells, invaded the whole of the 43-day testis (fig. 11). The sex cords were thus widely separated by a vascularized interstitial tissue. The testicular artery was one of the particularly interesting vessels irrigating the testis. Its centrifugal progress through the gonadal blastema was observed from the age of 38 days (fig. 4) up to its establishment in the newly formed tunica albuginea between days 40 ans 43 (figs 10, 11). There was a close correlation between the peripheral position of the testicular artery, with its mesenchymal accompaniment, and the growth of the tunica albuginea. At that time, the tunica albunginea developed, within 2 days, into a richly vascularized loose, thick mesenchymal tissue (fig. 11).

b) Ovary. Contrary to the testis, the structure of the young ovary was not greatly modified between day 40 and days 50 to 55 (fig. 13,14). The centrifugal differentiation of the sex cords continued but did not finish. The cords became thinner but retained an irregular organization. They developed only a discontinuous basal lamina

\section{PLATE IV}

\section{Ovarian differentiation}

FIG. 13. - A 39-day ovary. The beginning of sex cord differentiation in the gonadal blastema (g. b.) is the same as in the testis. Compare with figures 3 to $7 . \div 250$.

FIG. 14. - A 47-day ovary. From 40 days, differentiation is slow and incomplete as compared with the testis. The irregular sex cords are still in contact (arrows) with the peripheral epithelium (e). No tunica albuginea is visible, and most gonocytes (G) are poorly encircled by somatic cells. $\times 3000$. 
often interrupted at the level of the gonocytes which were incompletely surrounded by somatic cells (fig. 14). Thus, the tunica albuginea did not form, or rather, it remained in the state of a stippled anlage. It could be that the absence of a peripheral artery in the ovary similar to the testicular one, did nof favorize the future growth of this rudimentary tunica albuginea.

\section{Discussion.}

The first stages of differentiation of the Macaca fascicularis gonad (testis and ovary) during the period studied ( 36 to 55 days) corresponded completely with the histological sections described in Macaca mulatta by Van Wagenen and Simpson (1965), whose study on non-human primates is the only one in existence. However, those authors did not explain gonadal differentiation, which we have been able to do using serial semithin sections (fig. 15).
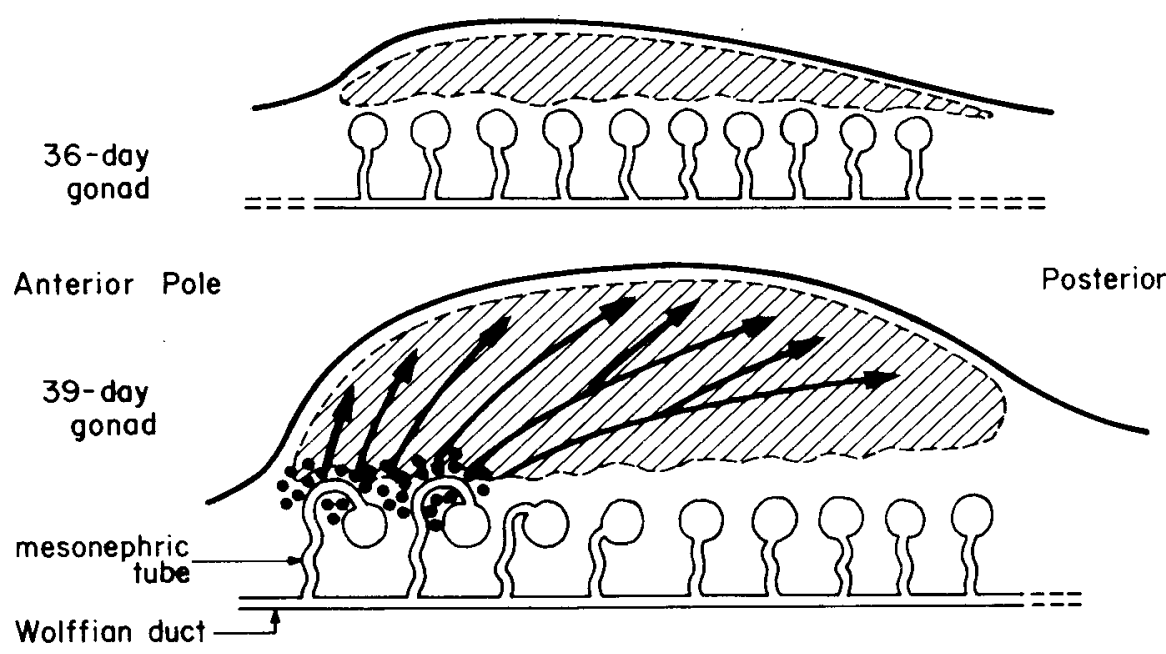

FIG. 15. - Diagram showing the early stages of fetal gonad (testis or ovary) differentiation in Macaca fascicularis. Arrows indicate the antero-posterior and centrifugal directions of cord formation from the perimesonephric mesenchyma of the anterior pole of the gonad. The dots represent perimesonephric cells. The hatched area indicates the limits of the central blastema of the gonad.

The first signs of gonadal differentiation appeared at about 37 days in the genital ridge already colonized by gonocytes. Within 2 days, the mesenchymal blastema of the gonad enlarged and differentiated into identical sex cord anlages in the testis or the ovary. Differentiation started in the immediate vicinity of the proximal loops of the mesonephric ducts at the anterior pole of the gonad. It then progressed both towards the posterior pole and centrifugally. The pictures suggested continuous colonization of the gonadal blastema by mesenchymal cells of the perimesonephros. These cells were annexed to preexisting cells and consolidated, combining among 
themselves and with the gonocytes. The cellular contacts were gradually narrowed and the blastema assumed a dense aspect, then split into sex cords which developed basal laminae.

The tubule or glomerulate cells did not seem to participate directly in the formation of the sex cords during the period studied. Their earlier cooperation at the genital ridge stage seemed unlikely according to the architecture of the first stages observed. However, only a study of the previous stages can decide this question. The contribution of peripheral epithelium cells to sex cord formation is not excluded, but, if it exists, it would be limited or secondary. The role of the epithelium appears to be proliferation to cover the growing gonad without ever forming peripheral cord anlages.

The analysis of gonadal differentiation in mammals and other vertebrates has produced some completely contradictory theories for more than a century. Reviews of Raynaud (1969), Jost (1972, 1973), Carlon and Stahl (1973) and Peters (1976) show that there is still disagreement on the origin and the role of somatic components as well as on the centripetal or centrifugal direction of cord differentiation. Different patterns of centrifugal sex cord differentiation, with the participation of the mesenchyma or the mesonephric ducts, were proposed some time ago (Carlon and Stahl, 1973). These concepts were recently confirmed in rats (Jost, 1972 ; Jost et al., 1973 ; Merchant, 1975), sheep (Zamboni ef al., 1979), mice (Upadhyay et al., 1979) and humans (Wartenberg, 1978). However, the modalities of mesonephric contribution were not exactly the same in the different species. Moreover, the participation of different somatic cell types in the formation of gonadal structures is difficult to determine because they all resemble each other. Artificial means, such as cell labelling (Merchant-Larios, 1979), are certainly very useful in determining the processes and in solving the doubtful cases.

These convincing results, obtained in various laboratories, only included a small number of species. It is too early to conceive of a single pattern of gonadal histogenesis. A better understanding of the processes and their possible unification may be reached in biochemical studies. The role of the sex chromosomes, and especially that of the HY antigen, in genetic control of gonad differentiation has not yet been completely elucidated (Wachtel, 1979).

On the other hand, the role of the mesonephros as the inductor of this process has been suggested in several reports (Jost, 1972 ; Peters, 1976). The mesonephros might have a dual role - that of emitting inductive substances and of furnishing cells to the gonadal anlage. The first type of action has not yet been confirmed. However, observations on macaques and other mammatian species clearly show that the gonadal anlage is truly occupied by different mesonephric cell types which are mesenchymal or epithelial.

Up to now, few authors have studied the relationship between vascularization and differentiation of the gonad (Pelliniemi, 1975). However, once the cord anlages are formed, their isolation is accelerated by mesonephric vascularization which then contributes to the specific patterning of each type of gonad. The role of vascularization is particularly clear in the testis. The mesenchymal accompaniment of mesonephric vessels produces a vast interstitium in which the Leydig cells differentiate from 50 days (Fouquet et al., 1978). Also, the appearance of the peripheral festicular artery 
must have some relation to the growth of the tunica albuginea in the testis. On the contrary, there is no peripheral artery in the ovary and practically no funica albuginea.

4th Workshop on « Development and maturation of the reproductive organs and functions 》

Luynes, France, octobre 1978.

Acknowledgements. - This work was supported by the DGRST (contract No 77-7-0671). The authors wish to thank Prof. $C$. Thibault for helpful discussion and criticism of the manuscript.

Résumé. L'histogenèse de la gonade fœtale de Macaca fascicularis a été suivie à partir du stade crête génitale chez 24 fołus ( 16 mâles et 8 femelles) âgés de 36 à 55 jours. Les observations ont été réalisées sur coupes sériées de spécimen inclus en Epon, par microscopie photonique et électronique.

La crête génitale est formée d'un blastème mésenchymateux recouvert par un épithélium périphérique. Les premières étapes de la différenciation (37-39 jours) sont les mêmes dans le testicule et dans l'ovaire. On observe une différenciation antéro-postérieure et centrifuge des cordons sexuels dans le blastème, à partir du mésenchyme périphérique des tubes mésonéphriques, au pôle antérieur de la gonade. La participation directe des tubes mésonéphriques ou de l'épithélium périphérique à l'édification des cordons sexuels paraît négligeable (PI. I).

Le partage des cordons néoformés est accéléré par l'invasion vasculaire venue du mésonéphros. La structure définitive du testicule est acquise entre 40 et 43 jours. La présence de l'artère testiculaire périphérique est déterminant dans la croissance de l'albuginée (PI. III).

L'ovaire ne subit plus de grandes modifications entre 40 et 55 jours (PI. IV).

\section{References}

CARLON N., STAHL A., 1973. Les premiers stades du développement des gonades chez l'homme et les vertébrés supérieurs. Path. Biol., 21, 903-914.

DANG D. C., 1977a. Absence of seasonal variation in the length of the menstrual cycle and the ferfility of the crab-eating macaque (Macaca fascicularis) raised under natural daylight ratio. Ann. Biol, anim. Bioch. Biophys., 17, 1-7.

DANG D. C., 1977b. Resumption of menstruation and fertility after cesarian in Macaca fascicularis. Ann. Biol. anim. Bioch. Biophys., 17, 325-329.

FOUQUET J. P., DANG D. C., MEUSY-DESSOLLE N., 1978. Functional differentiation of Leydig cells in the testis of the fetal monkey (Macaca fascicularis). Ann. Biol. anim. Bioch. Biophys., 18, 1205-1221.

JOST A., 1971. A new look at the mechanisms controlling sex differentiation in mammals. Johns Hopk. med. J., 130, 38-53.

JOST A., 1972. Données préliminaires sur les stades initiaux de la différenciation du testicule chez le rat. Arch. Anat. micro., 62, 415-438.

JOST A., VIGIER B., PREPIN J., PERCHELLET J. P. 1973. Studies on sex differentiation in mammals. Rec. Progr. Horm. Res., 29, 1-41.

MERCHANT-LARIOS H., 1975. Rat gonadal and ovarian organogenesis with and without germ cells. An ultrastructural study. Dev. Biol., 44, 1-21.

MERCHANT-LARIOS H., 1979. Origin of the somatic cells in the rat gonad : an autoradiographic approach. Ann. Biol. anim. Bioch. Biophys., 19, 1219-1229.

PELLINIEMI L. J., 1975. Ultrastructure of the early ovary and testis in pig embryo. Am. J. Anat., 144, 89-111. 
PETERS H., 1976. Intrauterine gonadal development. Fert. Steril., 27, 493-500.

RAYNAUD A., 1969. Les organes génitaux des mammifères, 149-636. In GRASSÉ P. P. Traité de zoologie, t. 16, fasc. VI, Masson et Cie Paris.

UPADHYAY S., LUCIANI J. M., ZAMBONI L., 1979. The role of the mesonephros in the development of the indifferent gonads and ovaries of the mouse. Ann. Biol, anim. Bioch. Biophys., 19, 1179-1196.

VAN WAGENEN G., SIMPSON M. E., 1965. Embryology of the ovary and testis in Homo sapiens and Macaca mulatto. Yale Univ. Press, New-Haven \& London.

WACHTEL S. S., 1979. H-Y antigen in the mammalian female. Ann. Biol. anim. Bioch. Biophys., 19, $1231-1237$.

WARTENBERG H., 1978. Human testicular development and the role of the mesonephros in the origin of a dual Sertoli cell system. Andrologia, 10, 1-21.

ZAMBONI L., MAULÉON P., BÉZARD J., 1979. The role of the mesonephros in the development of the sheep fetal ovary. Ann. Biol. anim. Bioch. Biophys., 19, 1153-1178. 